\title{
CNG INJECTOR RESEARCH FOR DUAL FUEL ENGINE
}

\author{
Adam Majczak', Grzegorz Barański', Ksenia Siadkowska', Rafał Sochaczewski²
}

1 Lublin University of Technology, Faculty of Mechanical Engineering, Lublin, Poland, e-mail: a.majczak@pollub. pl, g.baranski@pollub.pl, k.siadkowska@pollub.pl

2 Pope John Paul II State School of Higher Education in Biała Podlaska, Biała Podlaska, Poland, e-mail: r.sochaczewski@pollub.pl

Received: 2016.12.15

Accepted: 2017.02.01 Published: 2017.03.01

\begin{abstract}
The article presents the tests results of the prototype design of hydraulically assisted injector that is designed for gas supply into diesel engines. The construction of the injector allows for its positioning in the glow plug socket, so that the gas is injected directly into the combustion chamber. The cycle analysis of the four-cylinder Andoria ADCR engine with a capacity of $2.6 \mathrm{dm}^{3}$ for different crankshaft rotational speeds allowed to determine the necessary time for fuel injection. Because of that, it was possible to determine the required mass flow rate of the injector, for replacing as much of the original fuel by gaseous fuel. To ensure a high value of flow inside the injector, supply pressure equal to $1 \mathrm{MPa}$ was applied. High gas supply pressure requires high value of valve opening forces. For this purpose a injector with hydraulic control system, using a liquid under pressure for the opening process was designed. On the basis of air pressure measurements in the flow line after the injector, the analysis of opening and closing of the valve was made. Measurements of outflow mass of the injector were also carried out. The results showed that the designed injector meets the requirements necessary to supply ADCR engine with $\mathrm{CNG}$ fuel.
\end{abstract}

Keywords: CNG, diesel, gas flow, gas injector, dual fuel.

\section{INTRODUCTION}

Constantly rising oil prices and environmental considerations necessitate the search for new energy sources. One of the available solutions is a partial replacement of diesel fuel by compressed natural gas $(\mathrm{CNG})$ in the compression ignition engines. This type of the engines is used mainly in vans and trucks. These units are also gaining more and more popularity in the passenger car market. In Europe, this part of the market share reaches $50 \%$. Diesel engines are also used in industry in such means of transport as ship or locomotives. Diesel engines have higher emissions of nitrogen oxides in comparison to spark ignition engines. This can be currently limited by optimizing the combustion process and the use of additional systems, such as exhaust gas recirculation or AdBlue technology. As a result of the combustion process of diesel fuel also particulate matter (PM) that are harmful to the human health are emitted. Their emission is limited by the use of a particulate filter.

One of the method for reducing toxic components emission may be the use of liquid gas fuel, such as propane and butane (LPG) or compressed natural gas $(\mathrm{CNG})$. In addition to the environmental aspects, there are also economic reasons for the use of gaseous fuels to power diesel engines $[1,4,6]$. A total or partial replacement of diesel gas is possible. Depending on the used technology and the percentage of diesel fuel replacement it is possible to reduce the content of nitrogen oxides in the exhaust gas even by $30 \%$, particulate matter (PM) by $95 \%$ carbon monoxide and by $20 \%$, in relation to original diesel fuel [3]. 
The use of gas fuel in the diesel engine is much more complicated than in spark-ignition engines. For engines with indirect fuel injection, which currently represent the majority of the market, the installation of gas injectors in the inlet manifold and system calibration is only necessary for the conversion. Currently, engines with direct petrol injection are becoming more and more popular. In such engines it is much more difficult to carry out the conversion process to supply engine with the gas fuel, due to lack of space for gas injectors mounted in the cylinder head. Originally mounted gasoline fuel injectors also require cooling process which forces them to work from time to time.

Adaptation of the diesel engine for supply with the gas fuel is associated with similar problems. Additionally, because diesel engines are not equipped with an ignition device (spark plug in the spark ignition engine), when the lack of gas self-ignition ability occurs, there is a need to mount additional components such as spark plugs or to use a pilot dose of diesel fuel in order to initiate the combustion of the mixture [5]. In diesel engines there is also a no quantitative adjustment of injection, which causes the situation that for small engine loads the mixture is too lean, which prevents it from burning while for a high engine loads to rich mixture can leads to a knock combustion. Thus, from the technical point of view, the conversion of the diesel engine and its adaptation for gas fuel supply can be expensive and complicated. Nowadays, diesel engines are most often converted in two different ways. The first way is to adapt the engine to the process which occurs in a spark-ignition engine. In place of diesel fuel injectors, spark plugs are mounted, the compression ratio must be changed and the intake system must be equipped with a throttle. To ensure toxic emissions at an appropriately low level, three way catalytic converter must be mounted in the exhaust system. With this kind of changes the diesel engine becomes a spark-ignition engine. Changing the thermodynamic cycle results in a significant decrease in engine performance. The modernization carried out in such a way is very expensive and economically unjustified.

The diesel engine conversion may be also carried out without interfering with the structure of the engine. In this case, the gas fuel is burned together with original diesel fuel in the dual fuel mode. Indirect gas injection into the intake manifold or in the more sophisticated systems, direct injection into the combustion chamber can be used. Indirect injection system is considerably less complicated, unfortunately, it has some disadvantages, such as the occurrence of knock combustion and high emissions of exhaust toxic components resulting from the fact that part of the fuel entered into the exhaust pipe during the induction process. This is due to a long time of valves overlap, that is used in compression ignition engines. The best option in terms of economic, environmental and technical is the direct injection of gas fuel into the combustion chamber of the engine. In such systems, the gas is injected at high pressure at the end of the induction phase. This makes it possible to remove the remain exhaust gases from the cylinder and to obtain a high degree of cylinder filling with fresh air. Ignition is initiated by the pilot diesel fuel injected dose to the combustion chamber at the end of the compression stroke, while the main fuel is a gas. In the bibliography you can find many research results describing the operation of the diesel engine in dual fuel mode. The influence of the percentage use of the gas to the change of performance and toxic components emissions is described [4]. There are also studies showing the impact of pilot diesel fuel dose angle injection on the engine performance [1]. Due to the change in the type of fuel, diesel fuel injection angle correction, which initiates airgas mixture combustion is required.

The article presents the concept of the injector for the direct injection of compressed natural gas $(\mathrm{CNG})$.

\section{RESEARCH OBJECT}

The research object is a prototype gas injector designed for direct injection of compressed natural gas $(\mathrm{CNG})$ in compression ignition engines. The design of the injector allows to place it in the glow plug socket which significantly simplifies installation, so it is unnecessary to change the engine components. In order to ensure proper engine start-up parameters after removal of the glow plugs it is necessary to equip the engine with a device to heat the intake air. Other systems mounted in the engine do not require any changes. The presented injector conception is based on a hydraulic controlling of opening and closing process of the injector valve. Injector needle is the element that controls the gas flow. Its construction is similar to the construc- 


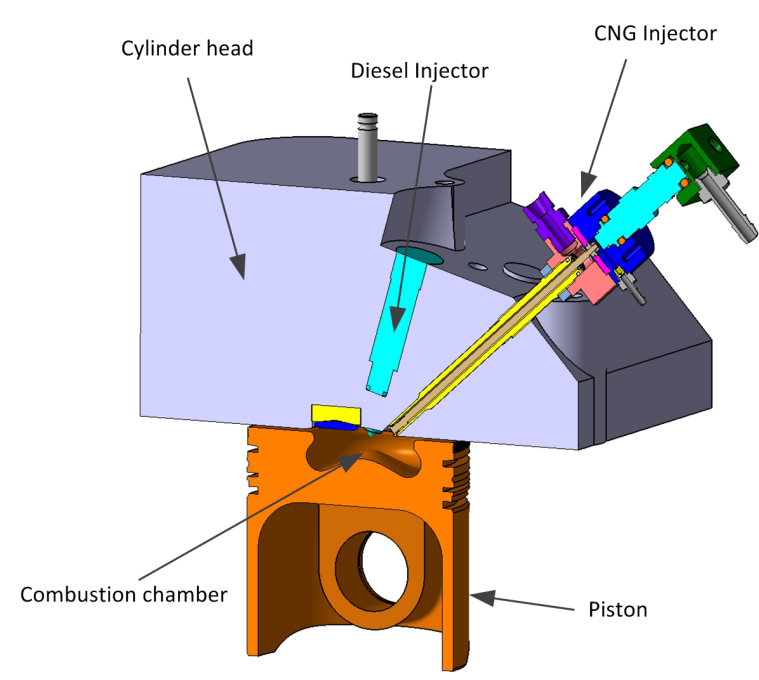

Fig. 1. The injector location in the cylinder head

tion of the engine valve. When the injector valve is closed the needle is contacting with the needle body thereby blocking the gas flow. Contact area of the needle and the body must be made with the accuracy ensuring tightness of connection. The needle body and the needle has been designed in such a way that it was possible to mount the injector in a standard glow plug socket. The glow plugs normally are located in the combustion chamber located in the piston which cause that the glow plugs have a significant length.

Developed construction of the injector allows screwing it into the socket of the glow plug while the injector body is located out of the cylinder head, what enables the free flow of gas from the injector into the combustion chamber. For better illustration of the location of the injector, the engine head model is presented in Figure 1. The needle in its upper part is connected with the control element. Opening of the injector is performed by filling the chamber located above the control element with a liquid. Increasing liquid pressure in the chamber causes the control element movement in the direction of the valve which leads to the needle movement from the needle body and the gas flow from the injector. The liquid flow from a chamber located above the control element is provided by a calibrated nozzle located in the injector body. The nozzle diameter determines velocity of opening and closing of the injector. For filling the liquid chamber a commercially available Bosch PFI liquid injector that is electromagneticallycontrolled was used. Gas and liquid injectors are separated from each other by a rubber membrane which provides seal and allows for movement of the injector needle along its axis. Designed injector is characterized by the possibility of obtaining a large needle lift, and the generation a high valve opening forces, which depends on the control element surface from the liquid chamber. The value of the injector opening force can be adjusted by changing the control element diameter. In addition, spring assisting valve closing is mounted in the injector body. A complete model of the injector and inceptor tip is shown in Figure 2. The control element, and the maximum height of the needle lift are shown in Figure 3. Needle lift regulation is provided by the regulation of distance between needle body and injector body. All the components of the actual injector are shown in Figure 4.

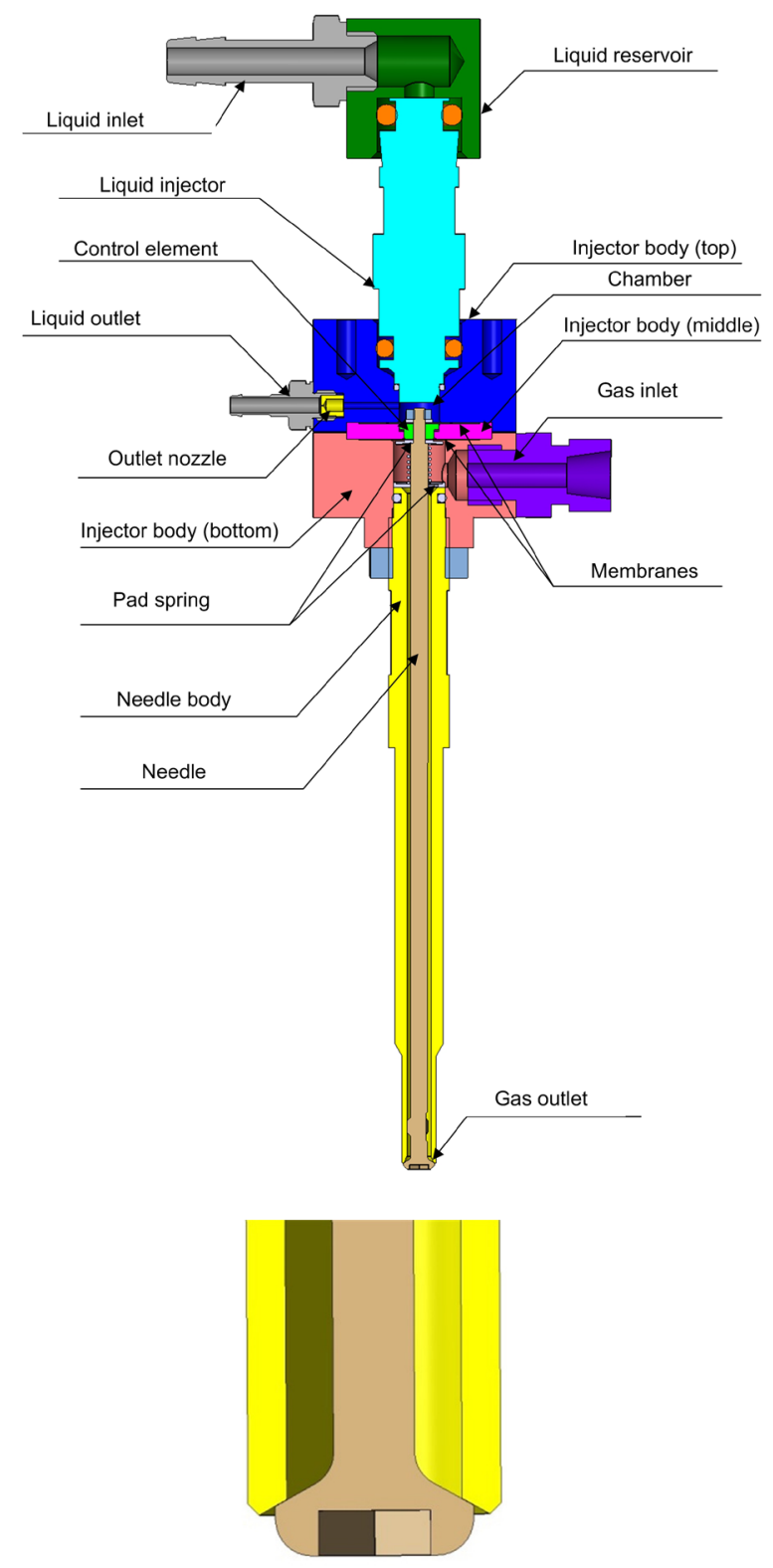

Fig. 2. Cross section of the injector and injector tip 


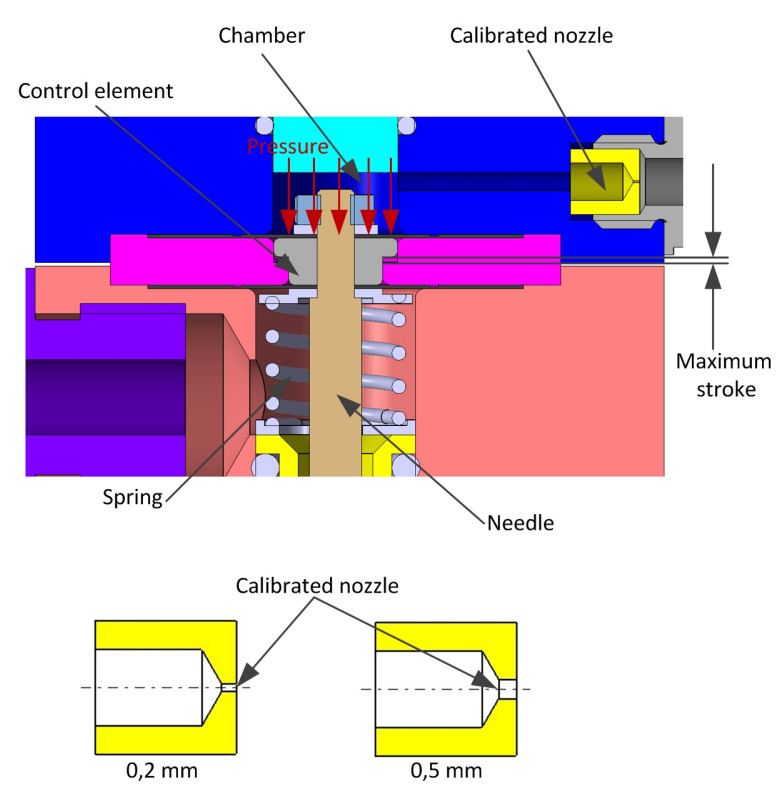

Fig. 3. Control element, maximum stroke and calibrated nozzle

\section{TEST STAND}

Tests were performed on a test stand designed to determine the characteristics of the gas injectors shown in Figure 5. The test stand consisted of air preparation system which includes: compressed air cylinders (15 MPa), the initial pressure reducer $(1.6 \mathrm{MPa})$, the second stage pressure regulator with filter allowing for precise adjustment of air pressure and air

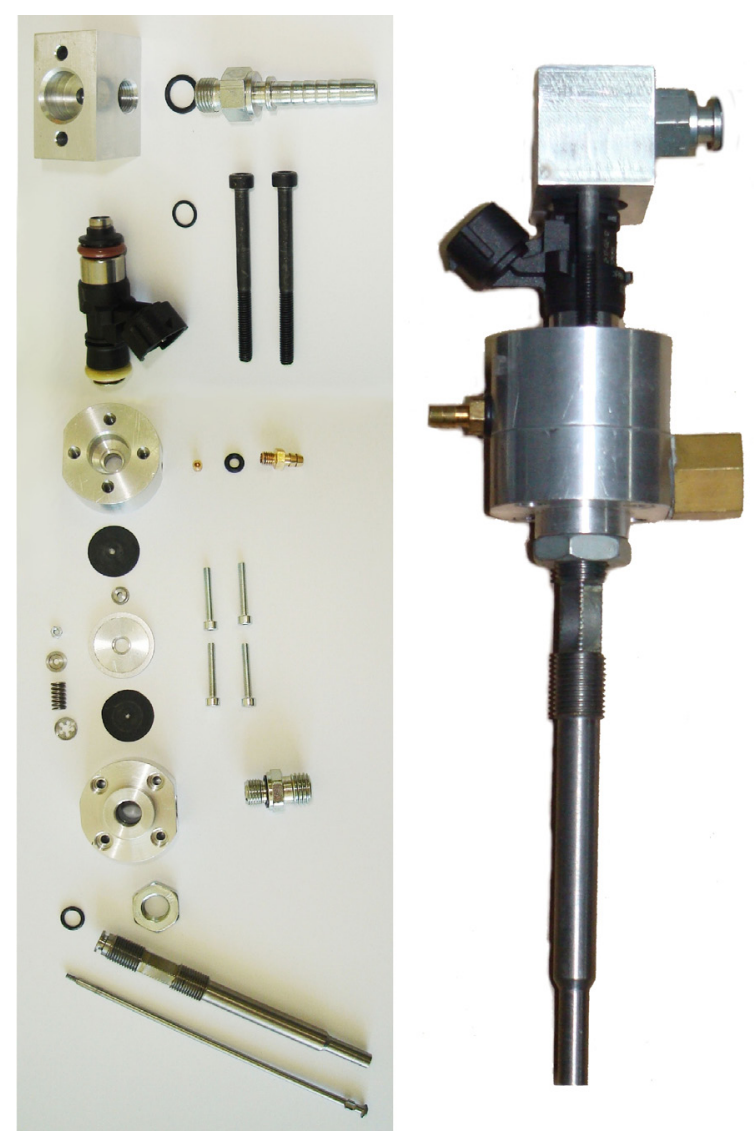

Fig. 4. Components of the injector

accumulator limiting pressure pulsations. Air preparation system is connected to the fuel rail and then to the tested injector. At each of the air preparation stages, pressure value registra-

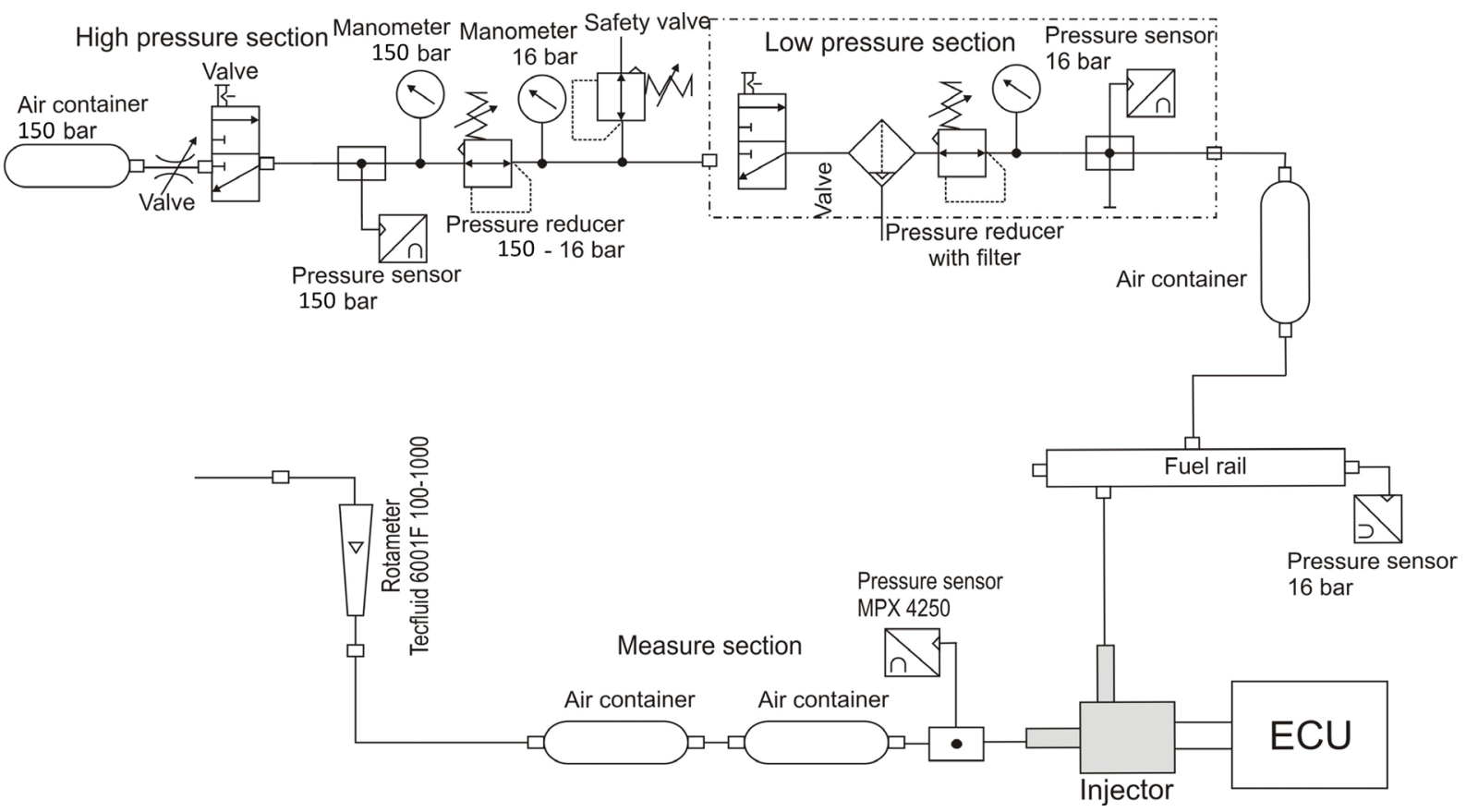

Fig. 5. Test stand 
tion is possible. At the outlet of the injector, a MPX 4250 pressure sensor with a measuring range from 0 to $0.25 \mathrm{MPa}$ of absolute pressure is mounted. This sensor is designed for fast changing measurements, which allows to specify the time of opening and closing of the injector. Injector mass flow measurement is carried out in section consisting of the rotameter and two air accumulators to restrict the air pressure pulsations. Control of the injector is realized by the control unit which allows for control of the liquid injector with any frequency and duration of the injection pulse. In addition, the test stand was equipped with a Tektronix TCP305 current probe with TCPA300 amplifier for determining the current value in the liquid injectors coil. All sensors and measuring elements were supplied with stabilized energy sources.

\section{RESEARCH OBJECTIVE AND SCOPE}

The aim of this study was to determine the flow characteristics of the hydraulically assisted injector. An analysis was conducted on the time available for injection in a 4-cylinder, Andoria ADCR turbocharged compression ignition engine equipped with a diesel common rail fuel injection system. The manufacturer of the engine is a Polish company Andoria-Mot Sp. with o.o. The main engine parameters are: displacement 2636 $\mathrm{cm}^{3}$, maximum power of $85 \mathrm{~kW}$ at $3700 \mathrm{rpm}$ and torque of $250 \mathrm{Nm}$ at $1800-2200 \mathrm{rpm}$. The engine meets the Euro 4 emissions standards.

Basic engine parameters are presented in table 2. Engine was originally equipped with glow plugs placed in the engine head so that it was possible to replace them by specially designed injectors. In order to accurately determine the time at which the gas will be injected it was necessary to determine the valve timing of the engine. Timing diagram is shown in Figure 6. To fully realize direct injection into the cylinder, the injection must begin after the closing of the exhaust valve, after the end of valves overlap. In this way, the phenomenon of fuel entry into the exhaust manifold was eliminated. Maximum time in which the gas can be injected depends on the engine crankshaft rotational speed. This engine is characterized by a crankshaft rotational speed within a range from $750 \mathrm{rpm}$ (idle speed) to $3800 \mathrm{rpm}$. Because of that, the duration of a complete cycle is between $12.5 \mathrm{~ms}$ and $68 \mathrm{~ms}$.
The maximum fuel injection time according to the engine rotational speed is shown in Figure 7. This calculation allowed the determination of the required gas amount needed for the implementation of the engine working cycle, depending on the degree of substitution of the original fuel. For Andoria ADCR engine adopted to the supply by a gas, $31 \mathrm{mg}$ must be provided for a $20 \%$ and $165.6 \mathrm{mg}$ for a $100 \%$ replacement of the original diesel fuel. It means that the gas fuel need to be injected with the mass flow rate in the range of $0.87-12.38 \mathrm{mg} / \mathrm{ms}$. Due to prototype version of the gas injector tests were carried out at a pressure value equal to $1 \mathrm{MPa}$.

Higher pressure values could lead to the destruction of the membrane separating the spaces filled with liquid and gas. Injection time was determined from the minimum value for which it was possible to observe the valve opening process, up to $8 \mathrm{~ms}$. Measurements were taken for four different liquid calibrated nozzles which diameters ranged from 0.2-0.5 mm. Injector flow rate was measured as air flow by using a rotameter and then this value was converted to a mass flow rate of the one injection process. Using the calculation coefficients, these values were calculated on the mass of the injected fuel in the case of

Table 1. Test conditions

\begin{tabular}{|l|c|}
\hline Injection pressure (gas) & $1 \mathrm{MPa}$ (diff.) \\
\hline Liquid injector & $\mathrm{PFI} \mathrm{BOSCH}$ \\
\hline Liquid injection pressure & $0,6 \mathrm{MPa}$ \\
\hline Injector needle stroke & $0,3 \mathrm{~mm}$ \\
\hline Outlet nozzle diameter & $0,2-0,5 \mathrm{~mm}$ \\
\hline Injection time & $2-8 \mathrm{~ms}$ \\
\hline Operating voltage (PFI Injector) & $12 \mathrm{~V}$ \\
\hline Operating current (PFI Injector) & constant \\
\hline Back pressure after injector & $0,1 \mathrm{MPa}$ \\
\hline Injection frequency & $15 \mathrm{~Hz}$ \\
\hline
\end{tabular}

Table 2. ADCR engine parameters

\begin{tabular}{|l|c|}
\hline Type & 4 stroke, diesel turbocharged \\
\hline Displaced volume & $2636 \mathrm{cc}$ \\
\hline Stroke & $95 \mathrm{~mm}$ \\
\hline Bore & $94 \mathrm{~mm}$ \\
\hline Compression ratio & $17.5: 1$ \\
\hline Number of Valves & 2 \\
\hline Fuel supply & Common Rail \\
\hline BSFC (max torque) & $210 \mathrm{~g} / \mathrm{kWh}$ \\
\hline
\end{tabular}




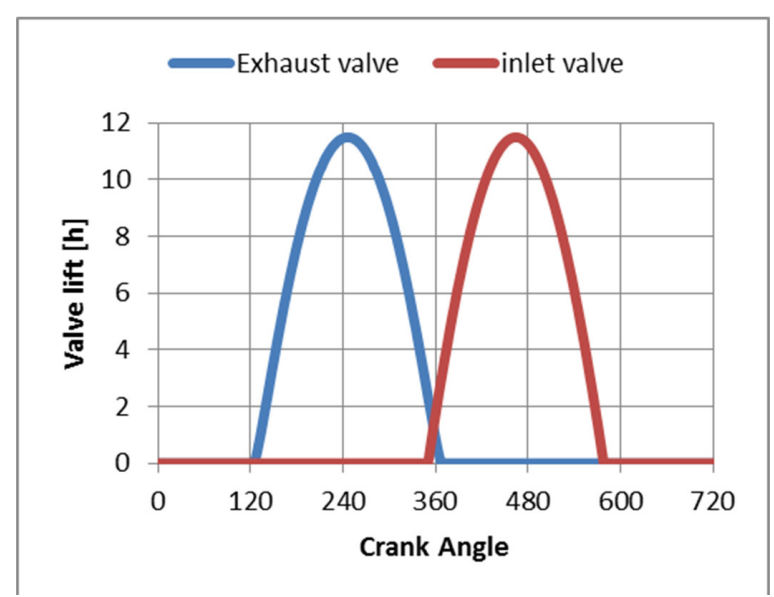

Fig. 6. ADCR engine valve timing

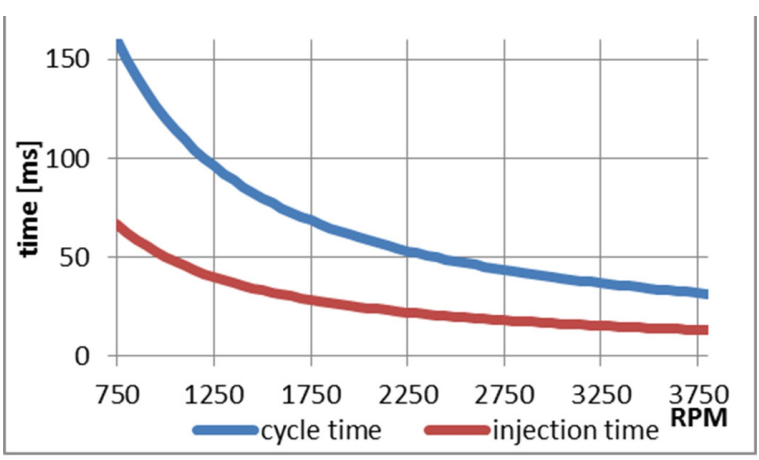

Fig. 7. Cycle duration and the maximum injection time

CNG using. Also, the time of opening and closing was analyzed, based on the pressure at the outlet of the injector. In the described case, it is not possible to measure the opening time of the injector by a vibration sensor [2]. Due to a completely different character of the valve opening as compared to a solenoid controlled injectors, it is not possible to determine the vibration characteristics and thereby the moment of full opening of the valve.

\section{RESEARCH RESULTS}

The research results were the injector flow characteristics as a function of injection time. During the study very large valve opening delay more than $3 \mathrm{~ms}$ was found. This is due to the long time of filling the pressure chamber and a continuous liquid outflow through the outlet calibrated nozzle. The flow rate characteristics of the injector was also made. The needle lift was set at 0.3 $\mathrm{mm}\left(3,42 \mathrm{~mm}^{2}\right.$ opening area). The characteristics of the injector depending on the used nozzle are shown in Figures 8-11.The injection mass was measured by calculating volume flow during the injections with constant frequency to one injection. Increasing of the nozzle diameter results in a lengthening of the injector opening time and a decrease in mass flow. The flow rate analysis of the injector showed a decrease with increase of nozzle diameter (Fig. 12). The analysis of the valve opening time and the closing time was possible due to the fast registration of the air pressure value after the injector. In Figure 13 an exemplary characteristics of pressure measurement after the injector outflow, current in the circuit of the liquid injector and a method for determining the delay of the valve opening and closing were shown. Time dependence of opening and closing of the valves, depending on the diameter of the outlet nozzle is shown in Figures 14-15. The nozzle diameter increasing extends the valve opening time, but decreases its closing time. The method of determining opening and closing time was described by [2].

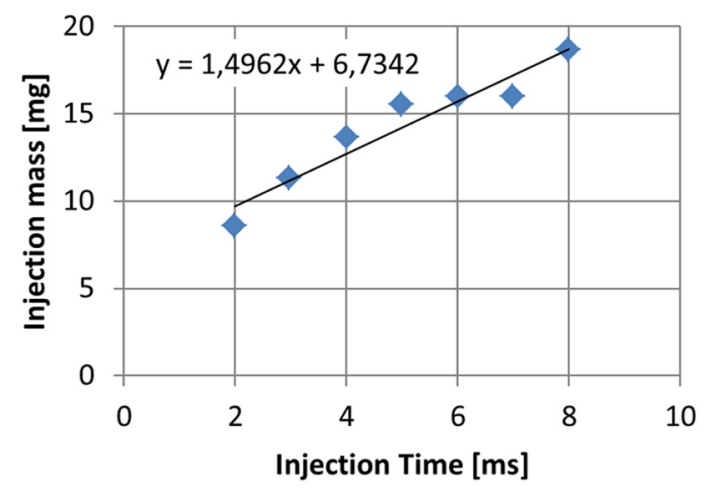

Fig. 8. Injector mass flow characteristics for $0.2 \mathrm{~mm}$ outlet nozzle (Injection pressure $1 \mathrm{MPa}$ )

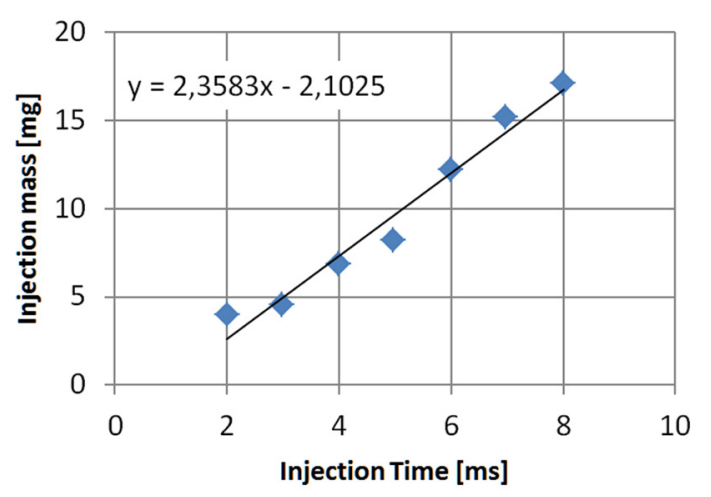

Fig. 9. Injector mass flow characteristics for $0.3 \mathrm{~mm}$ outlet nozzle (Injection pressure $1 \mathrm{MPa}$ ) 


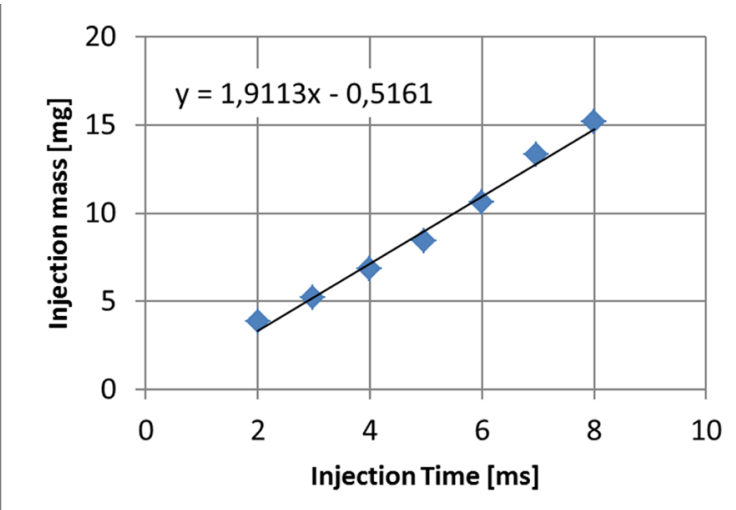

Fig. 10. Injector mass flow characteristics for $0,4 \mathrm{~mm}$ outlet nozzle (Injection pressure 1MPa)

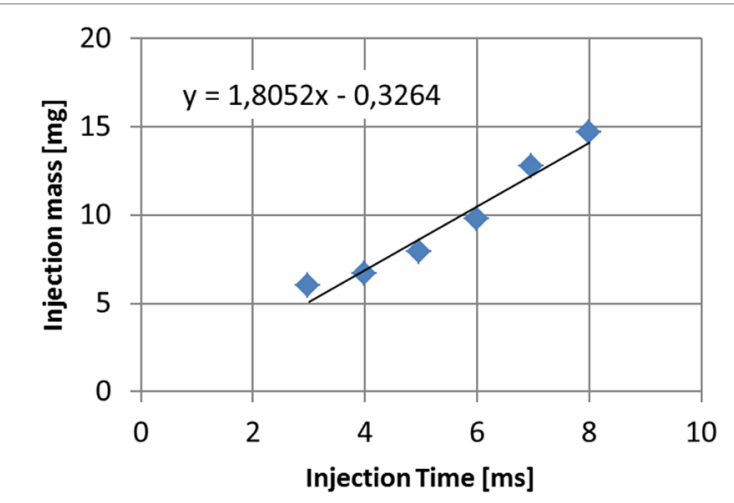

Fig. 11. Injector mass flow characteristics for $0,5 \mathrm{~mm}$ outlet nozzle (Injection pressure $1 \mathrm{MPa}$ )

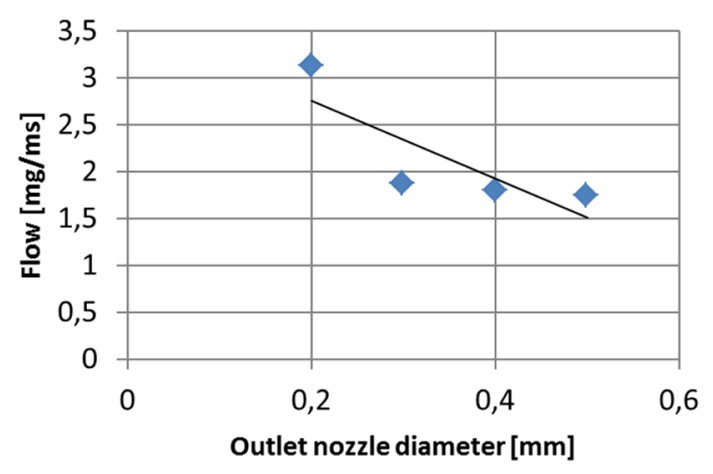

Fig. 12. Relation between injection flow rate and outlet nozzle diameter (Injection pressure $1 \mathrm{MPa}$ )

In none of the examined cases, the opening time is equal to the closing time, this is why the intersection point of the injector characteristics does not intersect with the $\mathrm{X}$ axis in the zero point. In the use of a nozzle with a diameter of $0.2 \mathrm{~mm}$, a significant delay in valve closing can be observed, what is caused by the small intensity

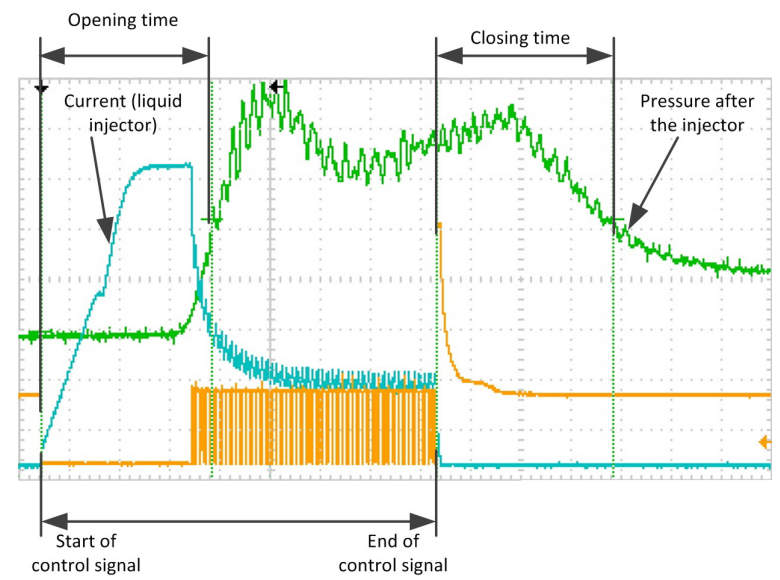

Fig. 13. Mean time course of measured values and method of definitions of opening and closing delay time

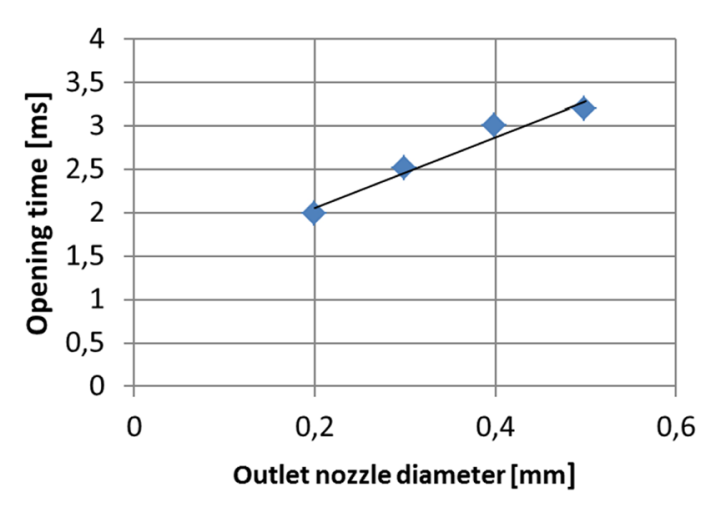

Fig. 14. Relation between injection opening delay time and outlet nozzle diameter (Injection pressure $1 \mathrm{MPa}$ )

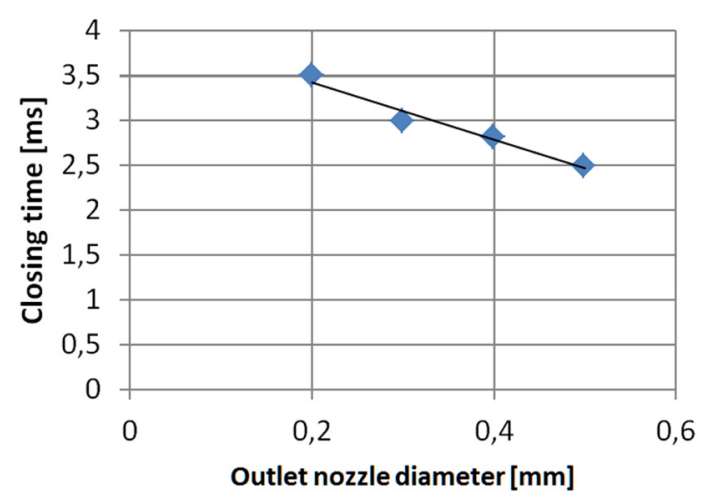

Fig. 15. Relation between injection closing delay time and outlet nozzle diameter (Injection pressure $1 \mathrm{MPa}$ )

liquid outflow. The difference between the time of opening and closing of the valve leads to many complications in the selection of the control algorithm in real conditions. 


\section{CONCLUSIONS}

As a result of bench tests and comparing the results obtained from the analysis of the requirements for the gas supply in the presented engine, it can be held that, an injector is not able to provide a partial replacement of diesel fuel in the whole range of engine operation conditions, because a large mass flow is required to inject necessary dose of gas. Mass flow reduction through the injector nozzle is caused by the small nozzle cross-section area which results from the needle lift. The construction of the injector does not allows to increase the maximum needle lift more than $0.3 \mathrm{~mm}$. Long time of valve opening is caused by a delay of filling the liquid chamber caused by too little fluid injector flow. Both, the times of opening and closing of the valve depends on the fluid injector nozzle diameter. Developed injector design that takes into account the changes to reduce the delay of valve opening and closing, and to increase outflow, can be used for further research both on the test bench and in the real world condition in the engine test bench. The described construction of the gas injector due to the very wide range of control parameters such as the force acting on the needle or needle lift, after the necessary modifications, can be used to supply diesel engines with compressed natural gas or other similar fuel.

\section{Acknowledgments}

This work has been financed by the Polish National Centre for Research and Development, under Grant Agreement No. PBS1/A6/4/2012.

\section{REFERENCES}

1. Barata J.M.M. Performance and Emissions of a Dual Fueled DI Diesel Engine. SAE Technical Paper, Series 952364, 1995.

2. Czarnigowski J., Barański G., Wendeker M., Duk M., Zyska T. Method to measure injector opening and closing lag times. Combustion Engines, 2011, 50 (1), 20-28.

3. Kajiwara M., Sugiyama K., Sagara M., Mori M., Goto S., Alam. M. Performance and Emissions Characteristics of an LPG Direct Injection Diesel Engines. SAE Technical Paper, Series 2002-010869, 2002.

4. Saleh H.E. Effect of variation in LPG composition on emissions and performance in a dual fuel diesel engine. Fuel 87, 2008, 3031-3039.

5. Stelmasiak, Z. Selected problems of application of natural gas to CI engine. Archiwum Motoryzacji, 2006.

6. Vijayabalan P., Nagarajan G. Performance, Emission and Combustion of LPG Diesel Dual Fuel Engine using Glow Plug. Jordan Journal of Mechanical and Industrial Engineering, 3 (2), 2009, 105-110. 